\title{
В.С. Федоров
}

Институт русской литературы РАН, Санкт-Петербург

\section{Феномен «Фаустовской Москвы» в метафизике Андрея Платонова}

На рубеже XIX - XX веков в России поднялась новая волна живого интереса к творчеству Гете, наряду с В.С. Соловьевым и Ф. Ницше, немецкий классик становится культовым художником русского духовного ренессанса. Писатели Серебряного века русской литературы, особенно символистского направления, - Бальмонт и Мережковский, Брюсов и Вячеслав Иванов, Андрей Белый и Эллис - не только активно изучают его творчество, не только переводят его на русский язык, но и заново пытаются перетолковать и осмыслить его поэтически-философский мир, а некоторые из них даже посвящают Гете отдельные книги [см.: Белый, 1917; Жирмунский, 1937; Зиммель, 1928; Метнер, 1914; Шагинян, 1923; 1950 и т.д.]. В начале 1910-х годов одним из центров гетеанства в России становится дом Метнеров в Москве и связанное с ним издательство «Мусагет». В мемуарах Белого мы читаем, что прадед Метнера - «артист, был знаком с Гете, которого Метнер боготворил». «...Он молился на Гете, мечтал едва ли не о «церкви» гетеистов; музей гетевских реликвий был ему «храмом» [Белый, 1990, с. 89, 100]. В этот период довольно тесно сближается с «Мусагетом» и Блок, который в «Краткой автобиографии» 1907 года писал: «Основные литературные влияния - Шекспир, Гете, Достоевский, Фет, Полонский, Вл. Соловьев, Вал. Брюсов» [Блок, 1963, с. 432]. Еще от своей бабушки Е.Г. Бекетовой Блок знал, что «тайный советник» Гете написал вторую часть “Фауста", чтобы удивить глубокомысленных немцев» [Там же, с. 30]. Неугасающий интерес к Гете поддерживал в Блоке и переписывающийся с ним отец, который призывал сына подражать прекрасным творениям Гете, его уравновешенности и объективному юмору. Своеобразным посредником между Гете и Блоком в продолжение всего творчества последнего был Ф.И. Тютчев, среди переводов которого имя немецкого писателя постоянно стояло на первом месте [см. об этом: Федоров, 1985, с. 29-42]. Уже после смерти Блока А. Белый писал о нем, что «“Фауст” в последние года ему был ближе и ближе, как и Гете вообще» [Белый, 1982, с. 812].

Сильнейшее влияние Гете испытал на себе и А. Платонов, который еще до Октябрьской революции, как и многие его современники, успел в полной мере вобрать в себя живительный воздух российской, в том числе и гетеанской, духовности. Удивительно, но вышеприведенные слова А. Белого о возрастающем с годами воздействии Гете и «Фауста» на творчество Блока в полной мере мы можем отнести и к Андрею Платонову. Следы очевидного гетевского присутствия у А. Платонова мы можем встретить повсюду - от самых ранних его произведений до самых последних. Гетевские мотивы в том или ином виде обнаруживаются нами везде: и в «Епифанских шлюзах», и в «Котловане», и в «Джане» и многих других произведениях автора. Но, видимо, наиболее яркое, наиболее всеобъемлющее воздействие немецкого классика, и здесь мы должны согласиться с Л. Дебюзер, прослеживается в «Счастливой Москве» А. Платонова. «Между прочим, весьма тонко замечает Л. Дебюзер, - “Счастливая Москва” в смысловом переводе 
на латинский означала бы: “Фаустовская Москва”, так как “фаустус” значит “счастливый”. “Фауст”, - констатирует немецкая исследовательница, - является в полном смысле всеобъемлющим шифром тайнописи романа и своеобразной связующей нитью между “Счастливой Москвой” и всеми пластами литературного подтекста, ибо Платонов, соотнося все остальные пласты непосредственно со “Счастливой Москвой”, одновременно пользуется фаустовскими пародиями своих предшественников. Платонов заново ставит вечные вопросы гетевской трагедии $<\ldots>$, проводя своих героев через главные проблемы человека и человечества современной ему эпохи» [Дебюзер, 2000, с. 630-632].

Вполне соглашаясь и с общими выводами статьи Л. Дебюзер, и с тем, что «через “Фауста" Платонов придает < ..> конкретным явлениям времени дополнительную художественно-историческую оценку и обобщение» [Там же, с. 632], к проблеме гетевского влияния в творчестве А. Платонова мы попытаемся подойти не со стороны внешнего, сюжетно-фабульного, отчасти психологического сопоставления Гете и Платонова, а со стороны внутреннего, метафизически-философского, религиозно-экзистенциального их родства и различия ${ }^{1}$.

Пристальный интерес к Гете, как мы уже отметили, А. Платонов пронес через всю свою жизнь. Влияние образов и идей Гете на творчество русского писателя сопоставимо лишь с тем огромным воздействием, которое имела на него Библия, и особенно ее новозаветная часть.

Гете интересовал Платонова прежде всего тремя аспектами своего разнообразного творчества. Во-первых, психологическо-метафизическим восприятием единства многообразного бытия. Во-вторых, своей гносеологией, своей открытой и гибкой методологией познания мира. И, в-третьих, отношением к сложнейшей проблеме двойственности, полярности, дихотомии бытия.

Рассмотрим все три указанные нами аспекта подробнее, попробуем хотя бы в общих чертах разобраться, что объединяло и что разделяло двух интереснейших классиков мировой духовной литературы.

В начале нашей статьи мы кратко сказали о том неоспоримом влиянии, которое оказал Гете на русскую литературу конца XIX - начала XX века, перечислили основные труды, которые вышли в это время в России и были связаны с именем великого немца. Думается, что со многими из них Платонов мог быть знаком. И все же, на наш взгляд, была еще одна работа, которая, по нашему мнению, сыграла самую большую роль в углубленном знакомстве Платонова с естественнонауч ным и религиозно-философским творчеством немецкого писателя ${ }^{2}$.

Речь идет о вышедшей в 1920 году в Петрограде в серии «Труды Социали стической Академии» объемной монографии В.О. Лихтенштадта «Гете. Борьба за реалистическое мировоззрение» [Лихтенштадт, 1920]. О первостепенном значении этой книги в качестве первой работы, познакомившей широкую общественность с научным творчеством Гете, писал и В.И. Вернадский: «Гете как ученый был выбран членом Московского общества испытателей природы при его основании (1805), Петербургского минералогического общества (1818) и позже, уже в старости, членом Петербургской Академии наук по физико-математическому отделению во время столетнего ее юбилея ${ }^{3} .<\ldots>$ Но широкие круги русской общественности, - по справедливым словам В.И. Вернадского, - могли ознакомиться с его научным значением только в XX веке (1920), когда молодой, погибший во время гражданской войны в 1919 г. гетеанец В.О. Лихтенштадт ${ }^{4}$ дал очень недур-

\footnotetext{
${ }^{1}$ О метафизике А. Платонова см.: [Федоров, 2001, с. 343-357].

${ }^{2}$ Подробнее о религии и философии Гете см.: [Федоров, 1988, с. 59-69; 1993].

${ }^{3}$ О связи Гете с Академией наук в Петербурге см.: [Дурылин, 1932, с. 211] и др., - а также статью Л.Б. Модзалевского в сборнике [Гете, 1937, с. 93].

${ }^{4}$ Краткие биографические сведения о В.О. Лихтенштадте см.: [Иванов, 1958, с. 91-92; Ионов, 1921].
} 
ной перевод главных мест его естественноисторической работы и попытался самостоятельно и своеобразно выявить вечное значение Гетеестествоиспытателя» [Вернадский, 1981, с. 252-253].

Платоноведами уже отмечалась несомненная связь А. Платонова с мировоззренческо-философскими взглядами А. Богданова, ${ }^{1}$ который, как и В.О. Лихтенштадт, признавал свое глубокое родство с Гете. В своем Предисловии к вышеуказанной книге В.О. Лихтенштадта А. Богданов говорит о несомненной «конгениальности» автора исследования духовному миру Гете. «Отражение Гете, - пишет А. Богданов, - которое дает эта книга, верно не только голой истиной факта, но и той, я бы сказал, художественной правдой, которая вытекает из органически-созвучного понимания» [Богданов, 1920, с. VI].

Главное, что объединяло и А. Богданова, и А. Платонова с Гете - это «органически-созвучное» понимание разнообразного бытия как единого целого и общие представления о методе познания окружающей действительности. Под влиянием Гете, а также «энергетической» философии В. Оствальда и «критической философии» Э. Маха А. Богданов не только в своих научных трудах («Эмпириомонизм», «Падение великого фетишизма», «Философия живого опыта»), но и в своих романах («Красная звезда», «Инженер Мэнни») еще задолго до революции утверждает центральную идею своего учения эмпириомонизма - мысль о физическом и психическом единстве мира. «Разве не возникает глубоких противоречий жизни, - задает риторический вопрос один из героев «Красной звезды», - из самой ограниченности отдельного существа по сравнению с его целым, из самого бессилия вполне слиться с этим целым, вполне растворить в нем свое сознание и охватить его своим сознанием!» [Богданов, 1986, с. 251]. В книге В.О. Лихтенштадта воспроизводится своеобразный гимн молодого Гете природе, с которым А. Платонов, вероятно, уже был знаком по «Письмам об изучении природы» А.И. Герцена (Письмо второе «Наука и природа - феноменология мышления»). Пытаясь, как и Гете, до последних основ постичь всеобъемлющую жизнь и природу, и вполне в духе немецкого гения, А. Платонов писал: «Люди хотят понять ту первичную силу, ту великую буйную мать, из которой все течет и рождается, откуда вышла и где веселится сама эта чудесная бессмертная жизнь...» [Платонов, 1988 , с. 542]. Всепроникновение жизнью было у этих писателей настолько значительным, что Платонов, и опять-таки в духе Гете, в своих произведениях не устает манифестировать свое удивительное мировосприятие, свое особое ощущение жизни как главную основу своего мировоззрения.

Любопытно отметить, что такое мировосприятие во многом разделял и А. Белый, книга которого о Гете также имела на А. Платонова значительное влияние $^{2}$. А. Белый, например, был искренне убежден в том, что, развивая «духовный тип» Гете, человек способен настолько подготовить свое самосознание, что сможет разговаривать с птицами, камнями, деревьями и даже с помощью «комплексаций» «преосуществить» еще небывалый феномен и вызвать перед собой «косми-

\footnotetext{
${ }^{1}$ См. работы Н.В. Корниенко, Е.А. Яблокова и др.

${ }^{2}$ Известно, что Гете вторую половину своей жизни занимался изучением света и цвета и почти двадцать лет писал самое объемное свое научное сочинение «К учению о цвете» («Zur Farbenlehre»). Более того, именно это свое научное детище, а вовсе не свои художественные творения, Гете считал самым ценным вкладом в культурную копилку человечества, этот труд, по его словам, давал ему «сознание превосходства над многими» [Эккерман, 1934, с. 190]. В упомянутой книге А. Белого («Рудольф Штейнер и Гете в мировоззрении современности») имеется большой материал, связанный с хроматикой Гете (см. главы «Гетев свет», «Праксис света», «Непосредственность света» и др.), а также показана связь державинской оды «Бог» со «Светом». О свете как преображающем начале земного естества много размышлял и А. Платонов, писатель мечтал о создании такого светотехнического механизма, который бы «свет, этот небесный поток» перерабатывал «в земной человеческий ток» [Платонов, 1988, с. 537-539].
} 
ческого» Христа [Белый, 1917, с. 90]! Здесь следует напомнить, что штейнерианская антропософия, которой одно время увлекался А. Белый, была смесью прежде всего гетеанства и гегельянства, но и здесь воздействие Гете было преобладающим. Сам Гегель открыто признавал, что своими воззрениями он был многим обязан Гете. В зените своей славы, в 1825 году, он писал автору «Фауста»: «Мне хочется назвать себя вашим сыном; у вас почерпала душа моя силу противоборствовать абстракции, ваши творения были сигнальными огнями на моем пути» [Гете, 1949, с. 12-13].

Однако, следуя во многом за Гете, А. Платонов сложнейший духовный материал всегда старался переосмысливать по-своему, по-платоновски, хотя и не считал нужным скрывать свою определенную, иногда очень большую, зависимость от предшественника. Так, «вслушиваясь» в мироздание, в тихие, почти неслышные шаги Универсума, Платонов иногда говорил словами самого Гете, о чем красноречиво свидетельствует и одно из названий его работы «Слышные шаги» [1921a], явно навеянное гетевским текстом. «Меня всегда чрезвычайно радует и утешает,- делится своими заветными мыслями немецкий писатель, - когда я вижу, что нежным душам всематеринская природа дает услышать в колебаниях своих гармоний также и чуть слышные и более нежные звуки и отзвуки, и столь различными путями дарит конечному человеку чувство вечного и бесконечного» [Лихтенштадт, 1920, с. 417]. Гете, читаем мы справедливые слова В.О. Лихтенштадта, «не допускал пропасти между живым и мертвым», вся природа для него была «жива и едина», и все же он с грустью вынужден был констатировать, что у его духа, «нет крыльев, чтобы взлететь до первоначал» [Там же, с. 39].

Но Платонов здесь пошел дальше Гете, он сумел найти те «крылья», которые помогли ему «взлететь до первоначал», реально, зримо, физически постичь экзистенциальную проблему бессмертия, спасительное «вещество мира».

«Вещество мира» художник постигал конкретно как нерасторжимое единство света, пространства и времени. О своем самом важном в жизни открытии он откровенно поделился с читателями в уже упомянутой нами статье «Слышные шаги (Революция и математика)», название которой, как вытекает из ее содержания, говорит не только о духовной зависимости от Гете, но и о полемике с ним. «Есть влекущая, обещающая много тайна в том, - писал в этой статье Платонов, - что пространство, по формуле Миньковского, равняется м н и м о й величине. Тут есть указание, закрытая дверь на большую дорогу» (выделено автором - В.Ф.). Поясняя, каким же образом ему все же удалось постичь праматерию, «вещество мира», Платонов продолжал: «Несовершенство нашего сознания в том, что я, например, не мог понять сразу эту формулу, а сначала почувствовал ее; ее истина не открылась для меня, а вспыхнула» [Платонов, 1988, с. 536]. «Вспыхнувшая» истина, - вот те «крылья», та изумительная сила, которая унесла Платонова к первоначалам, открыла для него сознательно-зримый, духовно-психический облик «вещества мира».

Открытие «вещества мироздания» приводит писателя и к пониманию высшей, более глубокой «сокровенности», чем сокровенность природы. «...Сокровенность природы, - пишет Платонов, - мертвое лицо, в котором нет жизни и нет загадки... Человеческой сокровенности одинаково чужды, в конце концов, и время, и пространство, и оно живет в звене между ними, в третьей форме, и только пропускает через себя пламенную ревущую лаву - время...» [Корниенко, 1995, с. 18] $]^{1}$.

Как мы отметили выше, Платонова с Гете объединяли не только общность материального восприятия мира, хотя, как мы пытались показать, с различным конечным результатом, с различной религиозной парадигмой, но и общий гибкий метод познания бесконечного разнообразия бытия. Гете, читаем мы в монографии В.О. Лихтенштадта, «подчеркивает символический характер всех научных поня-

\footnotetext{
${ }^{1}$ Подробнее о «трех» формах сокровенного см.: [Федоров, 2001a, с. 164-170].
} 
тий, теорий, гипотез, с помощью которых мы охватываем живой поток действительности» [Лихтенштадт, 1920, с. 56]. Это положение полностью разделяется А. Платоновым, который в 1922 году, в духе гносеологических воззрений Гете, писал: «Все научные теории, атомы, ионы, электроны, гипотезы - всякие законы вовсе не реальные вещи, а отношения человеческого организма ко вселенной в момент познающей деятельности...» [Платонов, 1988, с. 549]. Теория «принципиальных фальсификаций», по выражению Ф. Ницше, также много заимствовавшего у Гете, становится методологической основой гносеологии Платонова. Однако свобода в выборе гипотетичных идей и научных теорий для Платонова, как и для Гете, не являлась самодостаточной, схоластическая игра рассудка никогда не удовлетворяла его, интеллект для него всегда оставался лишь инструментом познания мира. В плане более глубокого теоретического обоснования целостной гносеологии писателя отметим, что, на наш взгляд, ближе всех к Платонову были воззрения П.А. Флоренского и крупнейшего русского философа-интуитивиста Н.О. Лосского. Последний, излагая взгляд Флоренского на способ познания истины, близкий и ему самому, писал: «Истину нельзя познать ни посредством с л е п о й интуиции, при помощи которой познаются разрозненные эмпирические факты, ни посредством дискурсивного мышления - стремления к сведению частичного в целое путем сложения одного элемента с другим. Истина становится доступ ной сознанию только благодаря р а ц и о н а л ь н о й интуиции, доводящей сочетание дискурсивной дифференциации ad infinitum с интуитивной интеграцией до степени единства» (выделено автором - В.Ф.) [Лосский, 1991, с. 233]. Две главные гносеологические «интуиции» Н. Лосского удивительным образом совпали с «двусмысленной» мыслью» не только «Счастливой Москвы», но и «двух пространств» Дванова.

Выявляя активное, волевое начало в акте познания, что было особенно важно для Платонова в первое пореволюционное десятилетие его творчества, П.А. Флоренский писал: «...акт познания есть акт не только гносеологический, но и онтологический, не только идеальный, но и реальный. Познание есть реальное в ы х ож д е н и е познающего из себя или, - что то же, - реальное в х о ж де н и е познаваемого в познающего, - реальное единение познающего и познаваемого. Это, отметил он, - основное и характерное положение всей русской и, вообще, восточной философии» (выделено автором - В.Ф.) [Флоренский, 1990, с. 78]. Из этих суждений П. Флоренского, похоже, известных писателю, напрашивается вывод, хорошо приложимый и к творческой эволюции Платонова. Если первую половину его творчества (до середины 30-х годов) можно охарактеризовать как попытку «выхождения» субъекта (художника и его героев) в объект (природу, Человека, Вселенную), то вторую половину его пути можно описать как «вхождение» (посредством Любви) «познаваемого в познающее», объекта в субъект.

И, наконец, третье, что объединяло Гете с Платоновым, это отношение к сложнейшей проблеме двойственности, двойничества, дихотомии бытия.

На протяжении всей своей жизни Гете непрестанно преследовало чувство душевной раздвоенности, двойственность была постоянной и характерной чертой его личности. После тяжелого душевного кризиса, который поэт пережил в тридцать восемь лет, он навсегда отказывается от идеи «чистой гармонии» и приходит к новой формуле бытия. Этой формулой становится для него идея полярности. Полярность видится ему во всем и везде: черное и белое, плюс и минус, притяжение и отталкивание - все это им воспринимается как «вдох и выдох мира, в котором мы живем, создаем и существуем». Но ведь и в душе человека та же полярность: доброе и злое, низменное и высокое, разум и чувства. И вот Гете не только констатирует «всемирное противоречие», но и начинает утверждать как благодат ную необходимость наличие в душе человека двух борющихся начал. Вот почему на первый взгляд отрицательный персонаж Мефистофель, по остроумному заме- 
чанию И.С. Тургенева, не сам «великий сатана», а «мелкий бес из самых нечиновных», - «творит добро, всему желая зла». Да и Бог, рассуждая о своем отношении к Мефистофелю, поручает ему вполне благородную задачу - «будить» Фауста, не наделяя, однако, беса сознанием его высокой миссии:

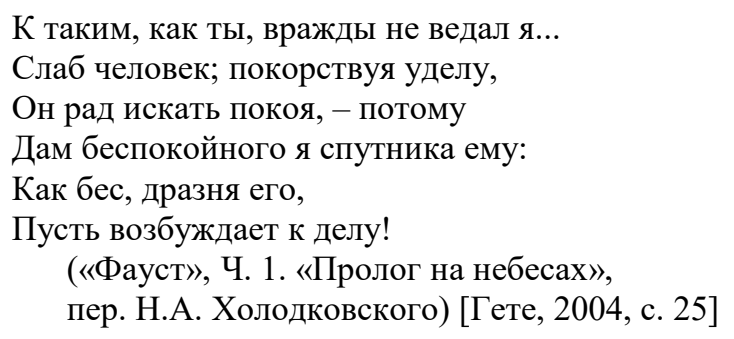

Итак, душа одна, но она вечно двоится. Фауст и Мефистофель - это две грани единого целого, необходимо дополняющие друг друга ${ }^{1}$.

А теперь зададимся вопросом: что же понимал под двойственностью А. Платонов, что объединяло и что разделяло его здесь с Гете, что скрывается за «двой ственностью» героев Платонова, в том числе «двойственностью» Александра Дванова, какой смысл автор «Чевенгура» вкладывает в говорящую фамилию этого центрального персонажа? Чтобы ответить на поставленные нами вопросы, а также глубже понять основную коллизию творчества Платонова до середины 30-х годов, необходимо эту проблему рассмотреть на трех семантических уровнях. Вопервых, «двойственность» говорит о глобальной дихотомии бытия, пронизывающей весь художественный мир платоновских произведений. Она показатель «рокового» разрыва всех связей живого, в том числе человека и природы, человека и Универсума. Во-вторых, это знак человека, по словам писателя, «двухстороннего действия», человека, заплутавшего своим схоластическим умом в сетях диалектического противоречия. И, в-третьих, это показатель практического отношения к миру несовершенной человеческой личности, разрывающейся между активным, теургическим началом, стремящимся создать «иную вселенную», и началом пассивно-созерцательным, сиротским, началом уставшей души, в конечном итоге доверяющей свое будущее «младой жизни, которая сыграет свой век не хуже нас» [Платонов, 1970, с. 35].

Уже при самом первом и самом общем сравнении «двойственности» у Гете и у А. Платонова видно, что, несмотря на то, что для обоих писателей она была наиважнейшей чертой их художественной метафизики, понимали они ее по-разному. Если в бинарной оппозиции Гете «полярность - нравственность» были равноправны оба бинарные члена, что дало основание С.М. Соловьеву упрекнуть Гете в том, что он не осознавал, что «мир во зле лежит», что «грех есть реальная сила» [Соловьев, 1917, с. 238-266, 478-522], то для Платонова в этой оппозиции прослеживается четкая иерархическая асимметричность в сторону нравственности: писатель никогда не мог согласиться с безнравственным «равноправием». Отсюда и разные экзистенциально-нравственные постулаты писателей. Если для Гете высшим мерилом нравственности был Бог Иисус Христос и вообще природный онтологизм, то для Платонова - метафизический человек, осознавший себя новоявленным Богом.

Если о «двойственности» первого и третьего семантического уровня в той или иной степени уже писали и говорили исследователи, то о двойственности, связанной с законом диалектики, известно немногое. Вспомним философский монолог персонажа из «Города Градова». «Стоит ли, - рассуждает бюрократ, - измышлять изобретения, раз мир диалектичен, сиречь для всякого героя есть своя

${ }^{1}$ Подробнее о двойственности в «Фаусте» Гете см.: [Федоров, 1993, с. 38-59]. 
стерва? Не стоит?.. Не есть ли сам закон или другое присутственное установление - нарушение живого тела Вселенной, трепещущей в своих противоречиях и так достигающей всецелой гармонии» [Яблоков, 1991, с. 15]. Подобная демонстрация диалектического закона противоречия в самых разных художественных формах и на всевозможных уровнях языкового выражения (слове - тексте контексте) встречается у Платонова постоянно. Так, например, и в «Чевенгуре» «мужики думали и так и иначе» [Платонов, 1991a, с. 160]. Думать «и так и иначе» для Платонова означало не просто констатировать некую вселенскую двойственность, как у Гете, а невозможность осознать эту двойственность как гармонию, пусть даже и потенциального бытия: получался всегда либо разрыв этой двойственности, либо ее смешение. В том же «Чевенгуре» один из персонажей, передавая содержание записки Копенкина, говорит: «Там товарищ Копенкин написал, что коммунизм и обратно» [Там же, с. 111]. Платоновский смысл этой странной фразы, как и вышеприведенных диалектических рассуждений бюрократа, становится понятным только после этимологического «обнажения» лексического значения ключевых слов и понимания основных положений философско-метафизической картины мира художника. По своему латинскому происхождению слово «коммунизм» означает «общий», «общинный», а слово «обратно», в контексте «бюрократической» диалектики, - «разобщенный», «отдельный». Так появляется первичный смысл платоновского текста, постулирующий постоянную и всеобщую борьбу синтеза и единичности, общего и отдельного.

И лирико-иронический тон повествования, и указание на несовершенство персонажей, сам контекст художественно-философской мысли писателя указывают нам на то, что «сокровенный» человек Платонова пытается не только теоретически, но и практически преодолеть этот «закон», ибо, задается вопросом писатель, не есть ли он «нарушение живого тела Вселенной». Другой герой Платонова, Епишка, активно пытается найти и утвердить свою вечную жизнь, но как это сделать, если человек живет в сетях поистине дьявольской диалектики: ведь из нее вытекает, что если есть жизнь, значит обязательно и непременно должна быть и смерть, а Епишка, несмотря ни на что, «хотел быть бессмертным». Однако не только желание бессмертия толкало платоновских героев к поиску выхода за пределы такого рода диалектики, но и нравственный закон в сердце: они не могли допустить, чтобы на каждого «героя» была своя «стерва». А ведь если «нет бессмертия души, - говорит герой Достоевского, - так нет и добродетели, значит все позволено». Имплицитная полемика с Кантом, связанная с вопросом о схоластической диалектике («чистом разуме») и темой бессмертия обнаруживается и в более позднем творчестве Платонова. В рассказе военного времени «Смерти нет!» герой произведения, резко возражая на припомнившуюся пленному немецкому офицеру «чужую фразу», говорит: «Чистый разум есть идиотство... Он не проверяется действительностью, поэтому он и «чистый»- он есть чистая ложь и пустодушие» [Платонов, 1970a, с. 350-351]. Кстати сказать, писатель четко различает «пустодушие» от «пустосердия». Если «пустодушие» это зацикленность человека на само го себя, отсутствие одухотворенности и явный признак мертвенности, отделения от окружающего многообразия бытия, то «пустосердие», связанное у художника с мягкостью, отсутствием твердости (ср. название рассказа «Железная старуха»), говорит о прямо противоположном. «Путешествие с пустым сердцем»- предварительное название первой части платоновского «Чевенгура», в котором герой романа Саша Дванов «себя самого, как самостоятельный твердый предмет, ... не сознавал... Своих целей он не имел... зато он без всякого внутреннего сопротивления сочувствовал любой жизни» [Платонов, 1991a, с. 66]. И герой «Счастливой Москвы» Сарториус также был «пуст». «Он думал о мыслях в чужой голове, шагал не своей походкой и жадно радовался пустым и готовым сердцем» [Платонов, 1991, с. 53]. Подлинно «сокровенный» человек, что было всегда принципиальной 
установкой Платонова, «должен быть пуст, чтобы смог вместить все» [Платонов, 1921].

Гете, и это также близко объединяло его с Платоновым, был одним из немногих мыслящих художников, который сознательно отделял себя как от всей схоластическо-умозрительной философии, так и от механическо-бездуховного позитивизма своего времени. Не объект и субъект, а природа и индивид - вот те понятия, которыми оперировал Гете. Совершенно прав был М.М. Бахтин, когда писал, что для Гете «Глубоко чуждо» противопоставление субъекта и объекта. «Познающий для Гете, - продолжает исследователь, - не противостоит познаваемому как чистый субъект объекту, а находится в нем, то есть является соприродною частью познаваемого. Субъект и объект сделаны из одного куска. Познающий, как микрокосм, содержит в себе самом все, что он познает в природе. <..> (Хайдеггер, например, - добавляет М.М. Бахтин, - считает "метафизическое" противопоставление субъекта и объекта главным пороком всего философского мышления нового времени)» [Бахтин, 1979, с. 396]. Ценя в философии Канта критику познающего субъекта, немецкий писатель отказывался признать ее положение об абсолютной непознаваемости явлений. Им не принимались ни кантовский трансцендентальный смысл идеи, ни панлогизм и антропоморфная метафизика Гегеля. Обновленный лейбницианско-гердеровским динамизмом и «органицизмом», религиозно-философский спинозизм Гете, преодолевая современный ему механицизм, учил гибкому, реалистическому пониманию мира, равным образом ускользая от односторонностей как идеализма, так и материализма. С изящным остроумием Гете в одном из своих писем к Шиллеру написал: «Мне всегда хочется думать, что если одна сторона никогда не сможет извне добраться до духа, то другая изнутри, едва ли достигнет тела, и поэтому будет всего правильнее оставаться в философском естественном состоянии и наилучшим образом пользоваться своим нераздельным существованием, покуда философы не договорятся, наконец, как можно воссоединить то, что они разделили» [Гете, 1949, с. 172]. Этим же гетевским духом пронизано и творчество А. Платонова. Устами Солнца Каспийская невеста (героиня «Рассказа о многих интересных вещах») зовет людей «побрататься, быть заодно с солнцем и звездами - и не надо будет ни работы, ни злобы, ни борьбы... Будет братство звезд, зверей, трав и человека...» [Платонов, 1984, с. 65]. Этот поистине гетевский «анимизм» исходил из рано сформировавшегося у Платонова представления о том, что «между лопухом, побирушкой, полевою песней и электричеством, паровозом и гудком, содрогающим землю - есть связь, родство, на тех и других одно родимое пятно... Рост травы и вихрь пара требуют равных механизмов» [Платонов, 1991a, с. 466].

Всеобщее одухотворение природы и метод познания мира были теми началами, которые в наибольшей степени объединяли Платонова с Гете. Что же касается «двойственности» бытия и решения экзистенциальной проблемы бессмертия, то здесь у них было отличие. Если для Гете «всемирное противоречие» и «полярность»- необходимые и неустранимые элементы логики и двигатель бытия, то для Платонова дихотомия бытия явление более многосложное и более «человеческое». Трагедия Гете «Фауст», по нашему мнению, вполне может рассматриваться не просто как главный «подтекст» «Счастливой Москвы», о чем справедливо пишет Л. Дебюзер, но и как основной метасюжет всего творчества А. Платонова, которое, как уже отмечалось исследователями, представляет собой единый контекст с переходящими идейно-образными константами. И действительно, сюжет «Фауста», в котором раздвоенная душа героя ищет выход к истине, подлинной жизни и бессмертию, к преодолению своей раздвоенности, а также завершение поэмы образ усыпанных розами детей («блаженных младенцев») как надежды Фауста на то, что в будущей жизни они завершат дело им начатое - все это, несомненно, объединяет Гете и А. Платонова. Однако общий сюжетный метазамысел и вообще 
отталкивание А. Платонова от какого-либо культурного подтекста не означало, что писатель буквально и слепо повторял известное. Наоборот, во многих случаях это означало не просто культурно-историческую иллюстрацию своих образов и идей, но и их коррекцию, а нередко и прямую с ними полемику. Так произошло и с «унаследованной» от Гете идеей «всемирного противоречия» бытия. Если для Гете эта проблема могла получить свое разрешение только в мирах иных, то для Платонова это труднейшее противоречие должен был разрешить сам человек уже на земле. Для Платонова двойственность это не просто диалектическая игра интеллекта, а как он определенно пишет в «Счастливой Москве» - объемное и самое глубокое видение «сокровенного» человека, его «двусмысленная мысль». Если для Гете проблема личного бессмертия решалась в деянии и пролонгировалась на неопределенное потустороннее будущее, связанное с энтелехией ${ }^{1}$, недаром Гете утверждал, что «убеждение в нашем дальнейшем существовании возникает из понятия деятельности» [Eckermann, 1884, S. 38-39], то для Платонова оно было связано с обретением все той же «двусмысленной мысли». Чувства-понятия «счастье» и «бессмертие» для Платонова были во многом близки и даже едины. И совершенно верно заметил М. Геллер, что Дванов был иногда счастлив, когда видел «одновременно» два пространства», пространство чувств и пространство мысли» [Геллер, 1982, с. 207].

Однако, если в методе познания мира писатели были едины, если проблема двойственности Платоновым, на наш взгляд, разработана глубже и, в определенном смысле, нравственнее, чем у автора «Фауста», если к конкретному решению экзистенциальной проблемы бессмертия Платонов подошел значительно ближе, чем Гете, то фоновое отношение к самой духовности, в широком смысле этого слова, к онтологизму было у них различным. И здесь гетевское мировидение, гетевское благоговение перед природой, при всей в определенной мере справедливой критике немецкого писателя С.М. Соловьевым, были той метанравственной вершиной, той высочайшей духовной константой, до которой Платонову дотянуться так и не удалось. Гетевский онтологизм оказался значительно ближе российской духовности (и в этом, на наш взгляд, главная причина постоянной популярности Гете в России), чем гилозоистическая метафизика трагико-комичных, сюрреалистических сочинений Андрея Платонова.

Основной конфликт, который в отличие от Гете Платонов активно стремился преодолеть, этот конфликт, связанный с всеобщей «разорванностью» бытия, с разъединяющими силами хаоса, с отьединенностью человека от жизни мирового Универсума. «Роковым силам» энтропии он пытался противопоставить объединяющий, спасающий космос эмпатии, одухотворения, всеобщие связи живой Вселенной. Характеризуя метафизически-философскую картину мира Платонова, мы можем констатировать, что перед нами во многом близкий к Гете антропоморфно-разумный гилозоизм, то есть ощутительное знание художником интеллектуально-живого антропоморфного вещества мироздания.

Платонов не строил иллюзий насчет легкости постижения реального, как он считал, человеческого бессмертия, да и сам он этой легкости никому не желал. Только труд, как и у Гете, напряженный духовный труд каждого человека, по мысли писателя, когда-нибудь приведет к равновесию «мысли и мира», к внутренней и внешней гармонии индивида и Бытия. Гетевское мировоззрение, гетевское восприятие природы было во многом близко духовному миру А. Платонова, чувствам, эмоциям и порывам мечтательной мысли его «сокровенных» людей. Гетевские идеи и образы через Ф. Ницше, О. Шпенглера, В. Соловьева, Н. Федоро-

1 Энтелехия (греч.) - сложное философское понятие, заимствованное у Аристотеля. Гете вкладывал в него представление о некой самостоятельной, неделимой сущности всех явлений природы, наделенной творческим потенциалом. Энтелехия (монада), считал Гете, присуща и человеку, но в разной степени своего проявления. 
ва, А. Блока, А. Богданова и многих других вольно или невольно постоянно «прорастали» в платоновском творчестве, оставляя заметный и важный след в его причудливо-странном, но всегда «прекрасном и яростном» мире.

\section{Литература}

Бахтин М.М. Эстетика словесного творчества. М., 1979.

Белый А. Рудольф Штейнер и Гете в мировоззрении современности. (Ответ Эмилию Метнеру на его первый том «Размышлений о Гете»). М., 1917.

Белый А. Дневниковые записи // Литературное наследство. Александр Блок. Новые материалы и исследования. Т. 92. Кн. 3. М., 1982.

Белый А. Начало века: Воспоминания: В 3 кн. Кн. 2. М., 1990.

Блок А.А. Собр. соч.: В 8 тт. Т. 7. М.; Л., 1963.

Богданов А. Предисловие // Лихтенштадт В. О. Гете. Борьба за реалистическое мировоззрение. СПб., 1920.

Богданов А. Красная звезда // Русская литературная утопия. М., 1986.

Вернадский В.И. Мысли и замечания о Гете как натуралисте // Вернадский В.И. Избранные труды по истории науки. М., 1981.

Геллер М. Андрей Платонов в поисках счастья. Париж, 1982.

Гете И.-В. Собр. соч.: В 13 тт. М.; Л, 1932-1949. Т. 13. М, 1949.

Гете И.-В. Фауст. СПб., 2004.

Гете. 1832-1932. Л., 1937.

Дебюзер Л. Тайнопись в романе «Счастливая Москва» // «Страна философов» Андрея Платонова: Проблемы творчества. Вып. 4. М., 2000.

Дурылин С. Н. Русские писатели у Гете в Веймаре // Литературное наследство. № 4-6. М., 1932.

Жирмунский В.М. Гете в русской литературе. Л., 1937.

Зиммель Г. Гете. М., 1928.

Иванов И.А. Марсово поле. Л., 1958.

Ионов И.И. В.О. Лихтенштадт. /Мазин/. Некролог. Пг., 1921

Корниенко Н.В. О некоторых уроках текстологии // Творчество Андрея Платонова. Исследования и материалы. Библиография. СПб., 1995.

Лихтенштадт В.О. Гете. Борьба за реалистическое мировоззрение. Искания и достижения в области изучения природы и теории познания. СПб., 1920.

Лосский Н.О. История русской философии. М., 1991.

Метнер Э. Размышления о Гете. Кн. І. М., 1914.

Платонов А. Вечер Некрасова в Коммунистическом университете Воронежская коммуна. 1921, 18 авг.

Платонов А.П. Слышные шаги. (Революция и математика) // «Воронежская коммуна». 1921а. № 12 от 18 янв.

Платонов А.П. Размышления читателя. М., 1970.

Платонов А.П. Смерти нет. М., 1970а.

Платонов А.П. Старик и старуха: Потерянная проза. Мюнхен, 1984.

Платонов А.П.Государственный житель: Проза, письма. М., 1988.

Платонов А.П. Счастливая Москва // Новый мир. 1991. № 9.

Платонов А.П. Чевенгур / Сост., вступ. ст. и коммент. Е.А. Яблокова. М., 1991a.

Соловьев С.М. Гете и христианство // Богословский вестник. 1917, февральмарт; апр.-май.

Федоров В.С. Блок и Гете // Блоковский сб., VI. Тарту, 1985.

Федоров В.С. Гете: черты мировоззрения // Философские науки. 1988. № 7.

Федоров В.С. В поисках Света и Вечности: О религиозно-философском феномене Гете // Мера. Литературный, религиозно-философский и историко-худо- 
жественный журнал. СПб, 1993. № 2.

Федоров В.С. Метафизический символизм Андрея Платонова // Русская философия. Новые исследования и материалы. (Проблемы методологии и методики) / Под ред. проф. А.Ф. Замалеева. СПб., 2001.

Федоров В.С. «Третья форма» сокровенного в художественной метафизике Андрея Платонова // Русский роман XX века; Духовный мир и поэтика жанра / Отв. ред. и сост. проф. А.И. Ванюков. Саратов, 2001а.

Флоренский П.А. Столп и утверждение истины. М., 1990. Т. І. Ч. І.

Шагинян М.С. Путешествие в Веймар. М.; Пг., 1923.

Шагинян М.С. Гете. М.; Л., 1950.

Эккерман И.П. Разговоры с Гете. Л., 1934.

Яблоков Е.А. На берегу неба (Роман Андрея Платонова «Чевенгур») // Платонов А.П.Чевенгур / Сост., вступ. ст. и коммент. Е.А. Яблокова. М., 1991.

Eckermann J.P. Gäspräche mit Goethe in den letzten Jahren seines Lebens. Jn 3 B. Leipzig, 1884. B. 2. 